\title{
The role of school building donors in financing education; Case study
}

\author{
Anvar Rasoleian ${ }^{1,{ }^{*}}$, Ebrahim Mansoori ${ }^{2}$ \\ ${ }^{1} \mathrm{MA}$, Department of management, Secretary of Education Mahabad city, Mahabad, IRAN \\ ${ }^{2}$ Assistant professor, Department of Accounting, Mahabad Branch, Islamic Azad University, \\ Mahabad, IRAN \\ E-mail address: Rasoulian1982@gmail.com
}

Keywords: School building donors, Financial capacity, Popular participation, Building schools.

\begin{abstract}
The current research was aimed at determining the role of school building donorsin financing education in the Western Azerbayjan. The present research is a survey type research and the statistical population of this research included all principals and deputies of education offices in the Western Azerbayjan who amounted to 144 people according to the announcement by the education site. To determine the volume of the sample, given the fact the statistical population was limited, all people were tested; however due to lack of cooperation by some of the subjects, the number of 100 people was chosen to compose the final sample. Data gathering was done by using the researcher made questionnaire for the variable of role of school building donors in financing education with the reliability coefficient of $0 / 828$. Also, to analyze the data, the SPSS software in proportion to the level of measurement, descriptive statistics at the descriptive level, and univariate $t$ coefficient at the explained analytical level were used. The results of testing the first hypothesis suggested that participation in school building affairs would reduce education related crises ( $\mathrm{Sig}=0 / 001)$; cash and non-cash contributions by donors would increase the educational financial power (Sig=0/001); elimination of existing obstacles and shortcomings would increase participation in school building affairs ( $\mathrm{Sig}=0 / 001)$ and reinforcement of spiritual and eternal motivation would cause motivation for building schools ( $\mathrm{Sig}=0 / 001$ ).
\end{abstract}

\section{INTRODUCTION}

Participation and how to fulfill it, though has roots in the early history of nations and different economic, social, cultural and political aspects of counties have been founded on popular participations, this concept today assumes a doubled importance. Some of the thinkers consider the principle pivot of development as being founded on participation by all forces within the community affairs (Matin, 2004). The Education as a social institution assumes a key role in development and education of human force; thus, attention to this major educational institution and drawing popular participation is of significance. Though in recent years we have observed peoples' participation in different fields of education, specifically in the area of school building division, we have a great distance to reach the objectives intended by participation (Steer and Wathne, 2010). Today, in our country peoples' participation in Education is highly necessary than any other time. This subject is on one hand related to the significance of the Education and the role this subject has in the country's national development and on the other and it relates to the insufficiency of budgets and state facilities regardless of the highest amount of national investment allotted to this sector (Matin, 2004). School building donors are considered to be intermediates between the state institutions and popular entities.

When the state, due to financial restrictions cannot construct or rebuild educational environments and on the other hand people appear to be frustrated of state's help to this sector, donors enter the arena and serve as a liaison between the state and popular institutions (Kadzaamira and Kunje, 2002). Currently, in the Western Azerbaijan, there are as many as 55 donor financed projects in cities of Khoy, Mahabad, Myandoab, Urmia, Piranshahr, Ushnavye, Makoo and Sardasht and we are witnessing a constructive competition with regards to drawing donors and construction 
of educational settings where the amount of credit allotted for these projects as we can conclude equals the amount afforded by the state. Of this number the number of 20 projects has seen a physical progress of over $20 \%$ (Tasnim news agency, 2014). According to the realities on the ground and financial restrictions of the Education and the significance of quantity and quality of the educational settings, it is imperative that Education officials reinforce existing ways for participation and identify other ways in order that they can account for Education needs in regard to constructions of schools. Therefore, in order to access ways of attracting more and more school building donors, to identify obstacles to participation and reinforce of motivation among them, to lay the ground for participation in Education and to disseminate this thinking among other people, it is suggested to seek the views of the school building donors at the national level. Although participation at the level of building schools does not account for all education related needs and problems, utilizing donors' experiences could lay the ground for appropriate planning for promotion of peoples in Education (Rose et al, 2013). This research aims to offer necessary recommendations for paving the way for popular participation within Education while identifying problems and obstacles to donors' participation. Much evidence indicates social financial resources are limited to the needs of the society. Hence, in many developing countries, the portion of the state budget and the National Gross Income assigned has seen a decline. Therefore, today this is an absolute reality that without people's participation and the private sector, even the most advanced countries will not manage to address the Education and thus to meet the educational needs (Ekrami Far, 2005).

Therefore, given the significance of participation in expanding educational environments and lack of sufficient facilities for accounting to educational spaces induced needs, one has to acquire new methods in regard to building schools through appropriate ways of drawing the popular participation and identification of donors and by using the experiences of other countries. Needless to say, in accordance with lack of sufficient budget by the state in the area of construction of educational spaces, the role of the school building donors in this regard is indispensable. For this, in this research attempts are done the fundamental question is answered: To what extent school building donors in the area of building educational spaces can strengthen the financial dimension the Education? Also, while seeking to find answers to the above question, some hypotheses are developed as follow:

- The role of donors in school building affairs will reduce education crises.

- Donors' cash and non-cash contributions will increase the financial capacity of the Education.

- Elimination of existing obstacles and shortcomings will increase participation in school building affairs.

- Reinforcement of spiritual and eternal motivations will induce motivations for building school affairs.

\section{RESEARCH LITERATURE}

\subsection{Domestic research literature:}

- Another research has been performed in the Markazi province in the area of relationship between benevolent (charitable) and the level of culture of each educational district (Bakhshi, 1995). The statistical universe of this studyincluded all participating donors in Education. The findingsrevealed that there is a positive relationship between the number of donors in each district a $\mathrm{d}$ the level of culture of that district. In the Markazi province, a research on the effects of education of parents' participation on the social development and students' educational achievement has been done. The findings indicated that if students' parents become familiar with participatory guidelines, this will affect their behaviors with their children.

- Another research in the Markazi province about effective manners of popular participation in education has been conducted. In this research, the usefulness of each of the popular participation manners in education were investigated and compared and the optimal participation manner was announced. For school builders, in this research the superb manner has been announced by school 
building charitable institution where the scope of the participation at the national level in on the rise. Another research has been conducted in the Hamadan province with regards to ways for attracting more popular participation in education. The findings revealed that with the increase of education among good doers, third level forparticipation will rise (Chahardooli, 2000).

- At the national district one area, a research was done which aimed at investigating expansion of popular participation culture in education, where the scope of this research involved six north western provinces. Research findings suggested the existence of difference between participation by teachers and parents in the provinces under study. A paper titled "obstacles to and ways for expansion popular participation in Education" has been written (Ghasemi Pooya, 2005). In this paper, internal and external shortcomings $f$ the Education have been cited and drawbacks arising from different schools and various parents and teachers' association, education councils and drawing participation and reinforcement of donors have been introduced a some of the internal education shortcomings. Another research titled "assessment of organizational position of popular participation within the Education structure" in the Fars province has been conducted (Iman, 2003). The researcher in this research has enumerated ways for drawing attention of the school building donors and obstacles and problems on this way. Ahmadi (2003) in a research has addressed the role of donors in constructing exceptional educational environments. This research which was formulated in form of an interview was conducted with one of the donors who were engaged in building exceptional educational schools and effective factors in donors' participation for creation of educational spaces specifically exceptional educational spaces were discussed. These factors were: sense of altruism, beliefs in decent deeds and that which remains in the Hereafter, strength of the society culture and development of social justice, love and interest in exceptional students and significance of and attention to effective Education.

- In a research, Matin (2004) addressed the quality of obtaining popular participation in building schools. In this research, firstly by reference to the fact that the Education financial resources do not suffice for desirable educational facilities, the effective role of popular participation in the area of investment with regards to the Education dimension has been addressed. Findings revealed that most popular participations have been in forms of cash contributions, land donation, construction of school building, house donation, equipment of schools, donation of material for construction and the like. Accordingly, donation of land and cash contributions isintroduced as successful ways for participation. Also, by means of the following method sintroduced we can expand school building processes: publicity and raising awareness, intellectual and scientific contributions, attraction of little aids and a short, medium and long term planning, paying homage to donors and reinforcement of donors' management over the popular participation section in school building, organization of participation arrangement. Ekrami Far (2005) also conducted a research on exploring donors' participation in offering services to the Education and obstacles and guidelines as well. This research was conducted with the aim of identification of ways for attracting popular participation with regards to construction and equipment of schools and the existing obstacles in this respect in the province of Khorasan. The research methodology is qualitative and descriptive and questionnaires were used for gathering data needed. Findings revealed that the most significant factor in drawing popular aids, from the view of education officials is raised level of beliefs, the statesmen being benevolent from the view of experts, raised level of beliefs in the view of potential donors, constructed schools by actual donors in the view of school principals, observance of respect and rights of donors from the perspective of the state and people and the most significant obstacles could involve non-intervention of donors in administering schools which they have built themselves, lack of a cooperation morale, inappropriate homage of donors, not having a proper model for helping the Education and lack of appropriate publicity respectively. Bozorgi and Daneshpoor (2010) addressed in a research dimensions of popular participation in Education. Findings revealed that factors for drawing the popular participation in helping education financially in the following need to be taken into account: drawing financial and intellectual contributions from people, creation of popular institutions while attracting donors, raising awareness of students, principals and teachers about the high stake task of school building, 
documentation of successful experiences of popular participation within the education affairs and utilization of national helpful experiences, and creation of an intimate and spiritual context which is quite useful for participation because participation is an emotional task. In another research, Matin (2004) explored and appraised ways for exploring popular participation in Education from the view of school building donors. Of most important objectives of this research was identification of drawing and expanding peoples' participation in Education, shortcomings, obstacles and elimination of drawbacks and strengthening of motivations for popular participation in building schools. This research was descriptive and fell in survey type researches. Findings revealed that planning for maintenance and creation of motivation among school donors and other people prone to participation, assessment and organizational reinforcement of school building women and men's association, training ways for drawing participation on the part of teachers, principals and students and elimination of red tape and laying the ground for expansion and facilitation of participation affairs are among the most significant ways form attracting donors' participation in the high stake task of school building.

\subsection{Foreign research literature:}

Gresberg, in a research with the subject of "expansion of effective participation of parents in Education" indicated that students' parents' participation in different school affairs has a constructive role in the success of the educational management. On the same basis, Gresberg demonstrated that major parts of rejuvenation and rebuilding of different parts of school are done with the aid of benevolent hands of the donors. Cotze, showed in a research that students' participation in the process of education highly contributes to better understanding, promotion of quality and increase of learners' satisfaction. Also, students' participation in processes of educational activities highly contributes to their social growth.

Steer and Baudienville (2010) in a research addressed the role of donors in financing primary education. Researchers first dealt with primary education problems at the global level and later, they stressed on the findings of education specifically the primary education. For this purpose, in accordance with the discussions presented in the paper, the researchers presented six key factors for better participation of donors in financing primary schools which are: 1) evidence and defense, 2) prioritization of participation and their management, 3) request for participation, 4) level of capacities for attracting participation, 5) development and structuring of contributions, 6), charitable organizations and their capacities. In the end, they state the role of the first three factors is more important. Rose et al (2013) has addressed in a research the very financing of global education. Most of the research is in relation with the statistics of high number of people deprived of healthy and high quality education. In this research, it has been stated that over 57 million children are deprived of education across the world and most of whom are placed in the delinquent and unhealthy children groups. Also, over 250 million children are deprived of healthy basic and high quality education. In the end, researchers offered the following guidelines for promotion of the quality of basic education at the global level: dissemination of strategic talks, improvement of information about data financing, facilitation of domestic resources and working out innovative financial affairs. For researchers, these are ways for reaching a global society with a high basic quality and in this course a lack of resources could be an obstacle to the fulfillment of this research. Steer and Wathne (2010) discussed the role of resources and financial providers in the primary education. Firstly, they stated that much progress has happened in recent years in the area of improvement of accessibility to then primary education and international support has been rising ever since. This paper refers to evidence $d$ reasons of lack of international cooperation and in the end, offers guidelines for improving the primary education and in the end their financing process. 


\section{METHODOLOGY}

The current research was aimed at determining the role of school building donors in financing education in the Western Azerbayjan. The present research is a survey type research which falls under applied researches. Since the research deals with the role of school building donors in education the methodology is context finding.

\section{RESEARCH POPULATION AND STATISTICAL SAMPLE}

The statistical population of this research included all principals and deputies of education offices in the Western Azerbayjan who amounted to 144 people according to the announcement by the education site. To determine the volume of the sample, given the fact the statistical population was limited, all people were tested; however due to lack of cooperation by some of the subjects, the number of 100 people was chosen to compose the final sample. Of this number 24 people were chiefs (principals) and 100 ones were serving as deputies in different offices. In this research, due to limited statistical universe, no sampling was done; as a result, all people constituted the statistical population. Of course, because the subjects were high ranking principals of education, hence a high number of questionnaires were not returned. For this, the statistical sample was reduced to 100 .

\section{RESEARCH TOOLS}

In order to gather data and information for analysis, a 45 question questionnaire was used. The first part of the questionnaire is related to demographic issues of the administrative systems like gender, marriage status, service record and the like whereas the second part relates to the role of school building donors in financing the education. The questionnaire covers four dimensions of role of donors in reducing educational financial problems, role of spiritual and eternal motivations for donors' participation, role of cash and non-cash contributions of the school building donors and elimination of existing obstacles and shortcomings facing donors for building schools. The questions have been designed in Likert close-ended five choice forms and cover different dimensions of research hypotheses. The reliability level of the research questionnaire is evaluated by means of SPSS software, version 18 and Cronbach's alpha. The reliability coefficient of the said questionnaire is $0 / 828$.Also, to analyze the data, the SPSS software in proportion to the level of measurement, descriptive statistics at the descriptive level, and single sample $t$ coefficient at the explained analytical level were used.

\section{FINDINGS}

Hypothesis 1: Participation by school building donors in school building affairs could reduce education financial problems.

Table 1. To investigate the effects of popular participation and their role in reducing financial problems of education, we used a univariate $t$ test where the results are provided

\begin{tabular}{|l|l|l|l|l|}
\hline \multicolumn{5}{|c|}{ Standard $t=20$} \\
\hline Variable & DF & Average & $t$ & Significance \\
\hline $\begin{array}{l}\text { Popular } \\
\text { participation }\end{array}$ & 99 & $28 / 810$ & $11 / 696$ & $0 / 000$ \\
\hline
\end{tabular}

As stated in table (1), the significance level of 0/000is significant at the $0 / 05$ level, i.e. the research hypothesis is accepted and the null hypothesis is rejected. As a result, as seen from the average obtained, the average obtained (28/810) is greater than the comparable average (20), indicating the positive role of popular participation in financing education. As a result, this hypothesis which deals with the role of popular participation in financing education states the more attention is paid to school building donors and the more attention is paid to popular participation, the better we can 
implement education school building policies and in this regard, donors can provide a major part of education related financial dimensions.

Hypothesis 2: Cash contributions and donations on the part of donors could reduce financial problems of the education.

To investigate the effects of cash contributions and donations on the part of donors in reducing financial problems of education, we used a univariate $t$ test where the results are provided in table2:

Table 2. Results related to single sample t test

\begin{tabular}{|l|l|l|l|l|}
\hline \multicolumn{5}{|c|}{ Standard $\mathrm{t}=12 / 5$} \\
\hline Variable & DF & Average & $\mathrm{T}$ & Significance \\
\hline $\begin{array}{l}\text { Cash } \\
\text { contributions } \\
\text { and donations } \\
\text { on the part of } \\
\text { donors }\end{array}$ & 99 & $15 / 741$ & $10 / 115$ & $0 / 000$ \\
\hline
\end{tabular}

As stated in table (2), the significance level of 0/000is significant at the $0 / 05$ level, i.e. the research hypothesis is accepted and the null hypothesis is rejected. As a result, as seen from the average obtained, the average obtained (1/741) is greater than the comparable average (12/5), indicating the positive role cash contributions and donations on the part of donors in financing education. As a result, this hypothesis which deals with the role of Cash contributions and donations on the part of donors in financing education states the more attention is paid to cash contributions and donations on the part of donors, the better we can implement education school building policies and in this regard we can expect that financial problems of the Education Will decline by the same rate.

Hypothesis 3: Elimination of existing obstacles and shortcomings will increase popular participation in school building affairs.

To investigate the effects of elimination of existing obstacles and shortcomings in increasing popular participation, the univariate $t$ test was applied.

Table 3. Results related to single sample t test

\begin{tabular}{|c|c|c|c|c|}
\hline \multicolumn{5}{|c|}{ Standard $t=47 / 5$} \\
\hline Variable & DF & Average & $\mathrm{T}$ & Significance \\
\hline $\begin{array}{l}\text { Elimination of } \\
\text { existing } \\
\text { obstacles and } \\
\text { shortcomings in } \\
\text { increasing } \\
\text { popular } \\
\text { participation }\end{array}$ & 99 & $72 / 669$ & $16 / 285$ & $0 / 000$ \\
\hline
\end{tabular}

As stated in table (3), the significance level of 0/000is significant at the $0 / 05$ level, i.e. the research hypothesis is accepted and the null hypothesis is rejected. As a result, as seen from the average obtained, the average obtained (72/669) is greater than the comparable average (47/5), indicating the positive role of elimination of existing obstacles and shortcomings in increasing popular participation. As a result, this hypothesis which deals with the role of elimination of existing obstacles and shortcomings in increasing popular participation states the more attention is paid to the elimination of existing obstacles and shortcomings in increasing popular participation, the better we can implement education school building policies.

Hypothesis 4: Reinforcement of spiritual and eternal motivations will lead to the creation of more motivation of donors for school building affairs.

To investigate the effects of reinforcing spiritual motivations on creation of donors' motivations, the univariate $t$ test was applied where the results are provided on then fooling table. 
Table 4. Results related to the single sample $t$ test

\begin{tabular}{|l|l|l|l|l|}
\hline \multicolumn{5}{|c|}{ Standard $t=17 / 5$} \\
\hline Variable & DF & Average & T & Significance \\
\hline $\begin{array}{l}\text { Reinforcement of } \\
\text { spiritual and } \\
\text { eternal } \\
\text { motivations }\end{array}$ & 99 & $26 / 826$ & $14 / 116$ & $0 / 000$ \\
\hline
\end{tabular}

As stated in table (4), the significance level of 0/000is significant at the $0 / 05$ level, i.e. the research hypothesis is accepted and the null hypothesis is rejected. As a result, as seen from the average obtained, the average obtained (26/826) is greater than the comparable average (17/5), indicating the positive role of reinforcement of spiritual and eternal motivations will lead to the creation of more motivation of donors for school building affairs. As a result, this hypothesis which deals with the role of reinforcement of spiritual and eternal motivations will lead to the creation of more motivation of donors for school building affairs states the more attention is paid to the reinforcement of spiritual and eternal motivations will lead to the creation of more motivation of donors for school building affairs, the better we can implement education school building policies.

\section{CONCLUSION}

According to the findings obtained from the hypotheses the research results are as follow: To investigate the effects of popular participation and their role in reducing financial problems of education, we used a univariate $t$ test. As stated in table 1, the significance level of $0 / 000$ is significant at the 0/05 level, i.e. the research hypothesis is accepted and the null hypothesis is rejected. As a result, as seen from the average obtained, the average obtained (28/810) is greater than the comparable average (20), indicating the positive role of popular participation in financing education. The findings of the current research are in one with those of research by Parvizian which deals with effective ways of popular participation in education. In the Parvizian research, the usefulness of each of the popular participation in education was investigated and the consequences were compared and an optimal participation manner was announced.

To investigate the effects of cash contributions and donations on the part of donors in reducing financial problems of education, we used a univariate $t$ test. As stated in table 2, the significance level of $0 / 000$ is significant at the $0 / 05$ level, i.e. the research hypothesis is accepted and the null hypothesis is rejected. As a result, as seen from the average obtained, the average obtained $(1 / 741)$ is greater than the comparable average $(12 / 5)$, indicating the positive role cash contributions and donations on the part of donors in financing education. The findings of the current research are consistent with those of Main (2002) who explored ways for ensuring popular participation in the school building affairs. Matin concluded that most popular participations have been in forms of cash contributions, land donation, construction of school building, house donation, equipment of schools, donation of material for construction and the like. Accordingly, donation of land and cash contributions is introduced as successful ways for participation.

To investigate the effects of elimination of existing obstacles and shortcomings in increasing popular participation, the univariate $t$ test was applied. As stated in table 3, the significance level of 0/000is significant at the 0/05 level, i.e. the research hypothesis is accepted and the null hypothesis is rejected. As a result, as seen from the average obtained, the average obtained (72/669) is greater than the comparable average (47/5), indicating the positive role of elimination of existing obstacles and shortcomings in increasing popular participation. The findings obtained are in conformity with those of Ekrami Far (2005) who examined donors' participation in school building. For Ekrami Far the major obstacles facing donors arenon-intervention of donors in administering schools which they have built themselves, lack of a cooperation morale, inappropriate homage of donors, not having a proper model for helping the Education and lack of appropriate publicity respectively, while the most significant guideline for attracting donors' participation to observe respect an rights of the donors by the state. 
To investigate the effects of reinforcing spiritual motivations on creation of donors' motivations, the univariate $t$ test was applied. As stated in table 4 , the significance level of $0 / 000$ is significant at the $0 / 05$ level, i.e. the research hypothesis is accepted and the null hypothesis is rejected. As a result, as seen from the average obtained, the average obtained (26/826) is greater than the comparable average (17/5), indicating the positive role of reinforcement of spiritual and eternal motivations will lead to the creation of more motivation of donors for school building affairs. The findings of this research are in line with those of Ahmadi (2003) who examined the role of donors in constructing exceptional educational spaces. This research which was formulated in form of an interview was conducted with one of the donors who were engaged in building exceptional educational schools and effective factors in donors' participation for creation of educational spaces specifically exceptional educational spaces were discussed. These factors were: sense of altruism, beliefs in decent deeds and that which remains in the Hereafter, strength of the society culture and development of social justice, love and interest in exceptional students and significance of and attention to effective Education.

In the end, in order to remove obstacles to donors' participation in school building and reinforce donors' motivation, it is necessary to eliminate administrative obstacles a $\mathrm{d}$ remove the problems facing the donors. Also, by appreciating the actions of the donors in this regard, appropriate steps need to be taken (e.g. holding conferences, ceremonies, visits and Mecca pilgrimage and pilgrimage of holy sites in Iraq and familiarity with each other for better interaction and provision of appropriate guidelines).

Also, according to the results obtained for more participation of donors in school building the following are recommended:

- According to the research findings and the positive role of donors in financing the education, it is recommended the culture of participation among different popular groups be disseminated.

- According to the research findings and the positive role of donors in financing the education, it is recommended fundamental measures be adopted for motivation and encouragement of donors.

- According to the research findings and the positive role of donors in financing the education, it is recommended donor assume powers for planning and decision making regarding school building affairs by themselves.

- According to the research findings and the positive role of donors in financing the education, it is recommended administrative stages relating to time consuming bureaucracy be removed or at eats minimized so that more donors are attracted.

- According to the research findings and the positive role of donors in financing the education, it is recommended appropriate conference be held at the city and national levels for reinforcing the motivation $f$ school building donors and also forappreciating this group of the society.

- According to the research findings and the positive role of donors in financing the education, it is recommended charitable associations of cities and provinces bee identified and attended to by officials.

- According to the research findings and the positive role of donors in financing the education, it is recommended the relationship between officials and donors become a persistent one.

- According to the research findings and the positive role of donors in financing the education, it is recommended in places where donors act to help the Education but the level of their help is low, the little help be covered by organization and management of the aids.

- According to the research findings and the positive role of donors in financing the education, it is recommended eternal and spiritual aspects become more salient in donor' activities.

- According to the research findings and the positive role of donors in financing the education, it is recommended the culture of school building be disseminated and be prioritized on the top of states' programs. 
${ }^{1}$ This Article sponsored by Assembly of school building donorsin Mahabad City has been performed.

\section{References}

[1] Ahmadi, K. (2003). Role of donors in building exceptional educational spaces, Journal of exceptional education, March and April, No. 8 and 9

[2] Bakhshi, A. (1995). Role of popular participation in the Education of Markazi province, Quarterly of Education.

[3] Bozorgi, K., \& Daneshpoor, N. (2010). Attitude to dimension of peoples' participation in Education, Bureau of cultural studies.

[4] Chahardooli, A. N. (2000). Exploring ways for attracting of popular participation in Education, Hamadan council of Education organization researches publication.

[5] Ekrami Far, M. R. (2005). Participation of donors in offering services to the Education; obstacles in guidelines, Journal of social sciences training growth, Winter, No. 25

[6] Ghasemi Pooya, E. (2005). Popular participation in Education, series of papers at the conferee of reforms in Education, Education research institute.

[7] Iman, M. T. (2003). Assessing organizational position of the popular participation in the Education structure, series of papers at the conference on engineering reforms in Education, Teaching research institute.

[8] Kadzamira, E. Ch \& Kunje, D. (2002). The Changing Roles of Nongovernmental Organizations in Education in Malawi, Centre for Educational Research and Training University of Malawi Zomba.

[9] Matin, N. (2004). Exploring the quality of ensuring popular participation in school building and national school structures.

[10] Rose, P., Steer, L., Smith, K., \& Zubairi, A. (2013). Financing for Global Education: Opportunities for Multilateral Action. Center for Universal Education at Brooking, United Nations Educational, Scientific and Cultural Organization, September.

[11] Steer, L., \& Wathne, C. (2010). Donor financing of basic education: Opportunities and constraints, Original Research Article International Journal of Educational Development, Volume 30, Issue 5, September 2010, Pages 472-480.

[12] Steer, L., \& Baudienville, G. (2010). what drives donor financing of basic education? Project Briefing. Overseas Development Institute. No 39, February.

[13] Tasnim news agency. (2014). 110 million dollar donation in school building affairs in western Azerbaijan, Fariborz Esmaeel Zade, Sep. 14 